www.nature.com/pj

\title{
Plant oil-based green composite using porous poly(3-hydroxybutyrate)
}

\author{
Nao Hosoda, Takashi Tsujimoto and Hiroshi Uyama
}

In this study, a plant oil-based green composite was developed using a porous bacterial polyester, poly(3-hydroxybutyrate) (PHB). The porous PHB with a topological fibrous structure was prepared via a simple technique that involves the dissolution of the polymer in dimethyl sulfoxide (DMSO) by heating and then subsequent cooling. The morphology and surface area of the porous PHB were dependent on the PHB concentration in DMSO. The porous PHB was impregnated via immersion with epoxidized soybean oil (ESO), and the acid-catalyzed curing of ESO produced a full bio-based composite that retained the porous structure of PHB. The resulting composites exhibited relatively good transparency, along with reinforcement of the plant oil-based network polymer. Furthermore, both the stiffness and toughness of the composites were improved by the incorporation of the porous PHB, suggesting good interfacial adhesion between the porous PHB and ESO polymer matrix. The present methodology of producing composites from renewable resources is expected to contribute to the development of bio-based materials in composite science.

Polymer Journal (2014) 46, 301-306; doi:10.1038/pj.2014.1; published online 5 February 2014

Keywords: epoxidized soybean oil; green composite; poly(3-hydroxybutyrate); porous material; reinforced material; renewable resource

\section{INTRODUCTION}

In recent years, the importance of renewable resource-based products for industrial applications has become extremely clear with the increasing emphasis on environmental issues, waste disposal and depletion of fossil resources. Bio-based polymers can provide an alternative to petroleum-based polymers by using innovative ideas in designing novel bio-based polymers and composites; these novel polymers and composites can compete with existing petroleum-based materials with the advantage of eco-friendliness. ${ }^{1-3}$

Plant oils, such as linseed, sunflower, soybean and palm oils, are some of the most abundant renewable resources, and hence, they are considered an ideal alternative chemical feedstock. ${ }^{4}$ Inexpensive triglyceride natural oils have been extensively utilized for coatings, inks, plasticizers, lubricants, resins and agrochemicals in addition to their applications in the food industry. ${ }^{5-7}$ However, the low functionality and flexible aliphatic nature of plant oils result in several limitations for thermosets, such as films with low mechanical properties. $^{8}$

Epoxidized soybean oil (ESO) is manufactured through the epoxidation of the double bonds of soybean oil, which is one of the most inexpensive vegetable oils in the world and is industrially available in large volumes at a reasonable cost. ${ }^{9}$ ESO is primarily used as a plasticizer for poly(vinyl chloride), chlorinated rubber and poly(vinyl alcohol) emulsions to improve stability and flexibility. ${ }^{10}$
Moreover, various cationic polymerizations of epoxidized plant oils can be achieved through the use of photoinitiators, latent catalysts or acid catalysts. These epoxy compounds from renewable resources possess a high potential as starting materials for bio-based thermosetting plastics. ${ }^{11-16}$ Epoxidized plant oils have been cured in the presence of inorganic chemicals to produce organic-inorganic hybrid materials. ${ }^{17-21}$ Furthermore, several researchers have investigated plant oil-based green composites using kenaf, flax, hemp and rosin derivatives as renewable compounds to improve their poor mechanical properties. ${ }^{22-25}$ We prepared a full bio-based composite by curing ESO in the presence of a poly(L-lactic acid) (PLLA) nanofiber mat. The nanoscale structural control over the PLLA fiber mat improved the mechanical properties of the plant oilbased network polymer. ${ }^{26}$

A series of poly(3-hydroxyalkanoate)s, including the poly(3-hydroxybutyrate) (PHB) homopolymer and the related copolymers, are naturally occurring thermoplastics that behave as intercellular carbon and energy storage compounds in microorganisms such as bacteria. ${ }^{27,28} \mathrm{PHB}$ is a highly crystalline and brittle polymer; however, it possesses a melting point and mechanical properties that are comparable with those of petroleum-based synthetic polymers. ${ }^{29,30}$ The brittleness of PHB is attributed to large spherulites and secondary crystallization. To overcome the shortcomings of PHB, PHB-related copolymers and the blend materials were developed. ${ }^{31-35}$ Recently, we reported the fabrication of a blend porous material of poly(3- 
hydroxybutyrate-co-3-hydroxyhexanoate) and polycarbonate. ${ }^{36}$ In this study, a porous PHB was prepared by thermally induced phase separation and was used as a reinforcement material for an ESObased network polymer. The resulting composites showed relatively good transparency, along with an improvement in their mechanical properties.

\section{EXPERIMENTAL PROCEDURE}

\section{Materials}

PHB $\left(\mathrm{Mw}=1.4 \times 10^{5}\right)$ was purchased from Sigma-Aldrich Co. (St Louis, MO, USA). ESO and a thermally latent cationic catalyst (benzylsulfonium hexafluoroantimonate derivative, Sun-Aid SI-60L) were gifts from the Mizutani Paint Co., Ltd. (Osaka, Japan) and the Sanshin Chemical Industry Co., Ltd. (Yamaguchi, Japan), respectively. Other reagents and solvents were commercially available and were used as received.

\section{Synthesis of ESO/PHB composite}

The following were typical procedures for the fabrication of PHB porous materials and the synthesis of ESO/PHB composites. PHB powder was dissolved in dimethyl sulfoxide (DMSO) at $90^{\circ} \mathrm{C}$ for $15 \mathrm{~min}$, and the solution was then cooled at room temperature. After $5 \mathrm{~h}$, the resulting white solid was washed with ethanol several times to obtain the porous PHB. For the synthesis of the $\mathrm{ESO} / \mathrm{PHB}$ composite, the porous $\mathrm{PHB}$ was immersed in ESO containing a thermally latent catalyst, followed by the removal of residual ethanol under reduced pressure at room temperature. Then, the sample was heated at $130{ }^{\circ} \mathrm{C}$ for $5 \mathrm{~h}$ to obtain the ESO/PHB composite.

\section{Measurements}

Scanning electron microscopy (SEM) was performed using a SU3500 (Hitachi High-Technologies Co., Tokyo, Japan) at an accelerating voltage of $15 \mathrm{kV}$. Nitrogen adsorption-desorption isotherms were measured using a NOVA4200e (Quantachrome Co., Boynton Beach, FL, USA), and BET
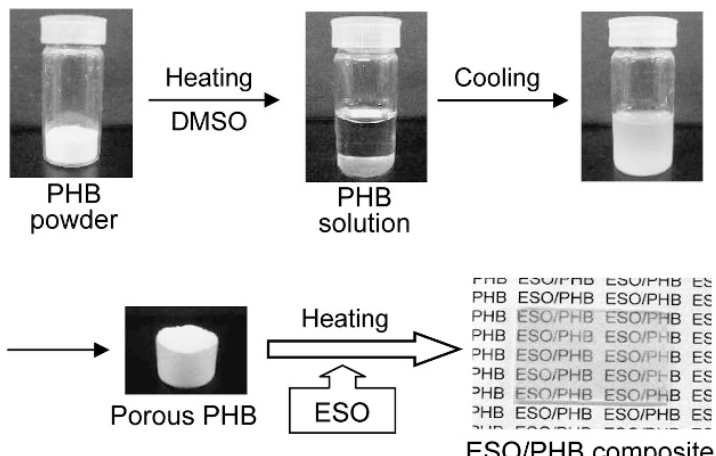

Figure 1 General procedure for preparing the porous $\mathrm{PHB}$ and ESO/PHB composite.
(Brunauer-Emmett-Teller) and Barrett-Joyner-Halendar analyses were performed with the Autosorb program. Fourier transform infrared spectroscopy was performed with a Nicolet iS5 (Thermo Fisher Scientific Inc., Waltham, MA, USA).

Thermogravimetric (TG) analysis was performed using a TG/DTA7200 (Hitachi High-Tech Science Co., Tokyo, Japan) at a heating rate of $10{ }^{\circ} \mathrm{C} \mathrm{min}{ }^{-1}$ under nitrogen. The thermal properties of the samples were measured under a nitrogen atmosphere using a DSC6220 differential scanning calorimeter (DSC) (Hitachi High-Tech Science). The sample was cooled at $-100^{\circ} \mathrm{C}$ for $2 \mathrm{~min}$ and then heated to $200^{\circ} \mathrm{C}$ at a heating rate of $10^{\circ} \mathrm{C} \mathrm{min}^{-1}$. Dynamic viscoelasticity analysis was performed using a DMS6100 (Hitachi High-Tech Science) with a frequency of $1 \mathrm{~Hz}$ at a heating rate of $3{ }^{\circ} \mathrm{Cmin}^{-1}$. Tensile properties were measured using an EZ Graph (Shimadzu Co., Kyoto, Japan) with a cross-head speed of $10 \mathrm{~mm} \mathrm{~min}^{-1}$. The sample was cut into sections measuring $40 \times 5 \times 1 \mathrm{~mm}$.

\section{RESULTS AND DISCUSSION}

\section{Fabrication of porous $\mathrm{PHB}$ material}

In this study, porous PHB was used as a reinforcement material for plant oil-based network polymers. Porous materials with a threedimensional interconnected framework have many exciting properties, including high specific surface area, high permeability, low density and fast mass transfer performance. ${ }^{37-46}$ Owing to these aforementioned properties, porous materials have received a considerable amount of attention in various fields, such as chromatography, catalysis and ion exchange. The porous PHB was fabricated using the thermally induced phase separation method. PHB is insoluble in DMSO at room temperature but soluble when heated. $\mathrm{PHB}$ powder was dissolved in DMSO at $90^{\circ} \mathrm{C}$. The solution was then allowed to cool at room temperature and was then washed with ethanol to yield a white porous PHB retaining the shape of the vessel. In this study, three samples of the porous PHB were prepared. The general procedure for the preparation of the porous PHB is illustrated in Figure 1. The morphology of the porous PHB was homogeneously macroporous, with a three-dimensional interconnected fibrous structure, which is shown in Figure 2. This unique structure could be derived from a precursor gel and attributed to the phase separation of the $\mathrm{PHB} / \mathrm{DMSO}$ solution during the cooling process, in which solvent-rich regions contributed to the formation of pores. However, with the higher PHB concentration, some heterogeneous coagulations of PHB were observed (Figure 2c).

Figure 3 shows a typical nitrogen adsorption-desorption isotherm of the porous PHB. The sharp nitrogen uptake near $P_{0}$ and the hysteresis loop in the $P / P_{0}$ range from 0.8 to 1.0 were observed, demonstrating the pore size distribution between mesopores and macropores. The surface area of the porous PHB, as determined by BET analysis, varied from 95 to $128 \mathrm{~m}^{2} \mathrm{~g}^{-1}$, and the formation of the
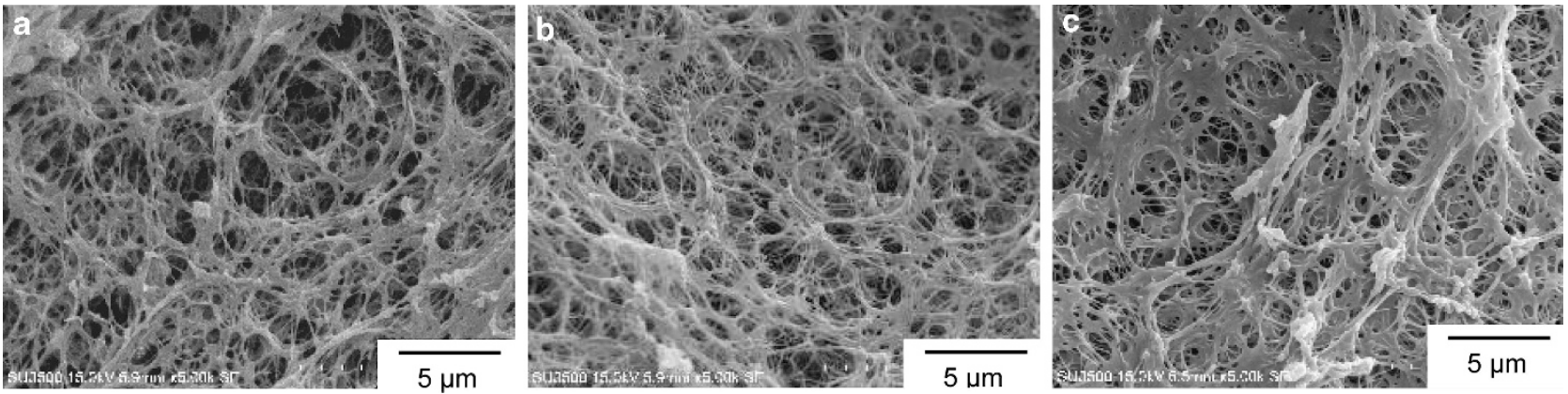

Figure 2 SEM images of porous PHB prepared from different concentrations of PHB in DMSO: (a) $50 \mathrm{gl} \mathrm{I}^{-1}$ (b) $100 \mathrm{gl}^{-1}$ and (c) $150 \mathrm{gl}^{-1}$. 
porous $\mathrm{PHB}$ was dependent on the $\mathrm{PHB}$ concentration in DMSO (Table 1).

\section{Synthesis of ESO/PHB composite}

An ESO/PHB composite was prepared by immersion. This method relies on the penetration of ESO into the porous PHB by diffusion. The oxirane group number for the ESO used in this study was 3.7 per molecule, as determined by ${ }^{1} \mathrm{H}$ NMR spectroscopy. For the synthesis of ESO/PHB composites, the porous $\mathrm{PHB}$ was immersed in ESO containing a thermally latent catalyst, and the crosslinking of ESO was performed at $130^{\circ} \mathrm{C}$, which was below the melting temperature of PHB. The resulting composites showed relatively good transparency, suggesting full impregnation of ESO and a uniform distribution of PHB in the ESO polymer matrix. In the Fourier transform infrared spectrum of the $\mathrm{ESO} / \mathrm{PHB}$ composite, a peak at $823 \mathrm{~cm}^{-1}$ that

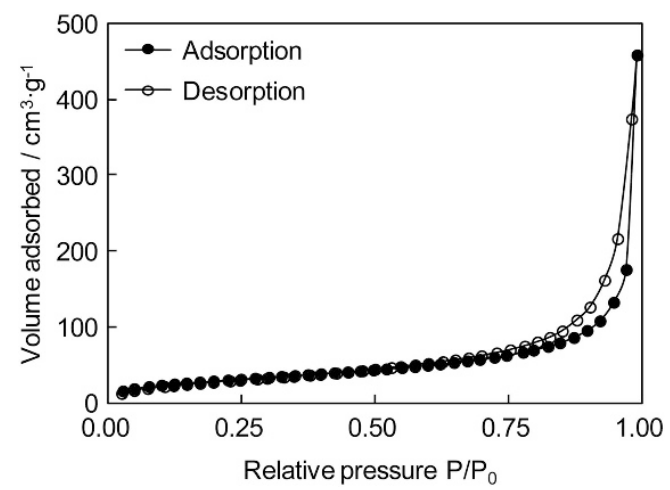

Figure 3 Typical nitrogen adsorption-desorption isotherm of porous PHB (PHB concentration: $100 \mathrm{gl}^{-1}$ ).

Table 1 Properties of porous PHB and ESO/PHB composite

\begin{tabular}{|c|c|c|c|c|}
\hline \multirow[b]{2}{*}{ Code } & \multicolumn{3}{|c|}{ Porous PHB } & \multirow{2}{*}{$\begin{array}{c}\text { Composite } \\
\text { PHB } \\
\text { content }^{\mathrm{b}, \mathrm{c}} / w t^{2} \%\end{array}$} \\
\hline & $\begin{array}{c}\text { Concentration }{ }^{\mathrm{a}} \\
\mathrm{g} \mathrm{I}^{-1}\end{array}$ & $\begin{array}{c}\text { Surface area/ } \\
\qquad m^{2} g^{-1}\end{array}$ & $\begin{array}{l}\text { Pore volume/ } \\
\qquad \mathrm{cm}^{3} \mathrm{~g}^{-1}\end{array}$ & \\
\hline ESO homopolymer & - & - & - & 0 \\
\hline ESO/PHB-50 & 50 & 128 & 0.52 & 5 \\
\hline ESO/PHB-100 & 100 & 107 & 0.71 & 11 \\
\hline ESO/PHB-150 & 150 & 95 & 0.33 & 19 \\
\hline
\end{tabular}

aPHB concentration in DMSO.

bPHB content of ESO/PHB composite.

'Determined by TG analysis. corresponds to a $\mathrm{C}-\mathrm{C}$ antisymmetric stretch of the oxirane groups of ESO was not observed, and a broad peak centered at $3400 \mathrm{~cm}^{-1}$ was observed due to an $\mathrm{O}-\mathrm{H}$ stretch. These data indicate that the oxirane groups reacted with each other to form a plant oil-based network structure. Moreover, two peaks at 1723 and $1743 \mathrm{~cm}^{-1}$, which are attributed to the $\mathrm{C}=\mathrm{O}$ stretches of the carboxyl groups of the ESO polymer and $\mathrm{PHB}$, respectively, were observed (see the Supplementary Figure S1).

Figure 4 presents the SEM images of the fracture surface of the ESO homopolymer and the ESO/PHB-100 composite. The ESO homopolymer was brittle, and the fracture occurred where a crack spread easily and freely. The fracture cross-section of the ESO homopolymer showed a smooth and uniform surface. However, the SEM image of the ESO/PHB-100 composite showed a dense filling of the fibrous protrusions that are attributed to the porous PHB.

Thermal and mechanical properties of ESO/PHB composite Thermal degradation of the ESO homopolymer, the porous PHB and the ESO/PHB composites was investigated using TG measurements (Figure 5). TG traces of the ESO homopolymer and the porous PHB showed weight loss due to the thermal decomposition at 270 and $400{ }^{\circ} \mathrm{C}$, respectively. Almost no residues were observed at $500{ }^{\circ} \mathrm{C}$. It was found that the ESO/PHB composites decomposed through a twostage weight loss process, with the first weight loss occurring at $\sim 300^{\circ} \mathrm{C}$ and the second one at $\sim 400^{\circ} \mathrm{C}$. Comparing the traces of the ESO/PHB composites with those of the ESO homopolymer and the porous $\mathrm{PHB}$, the first and second weight losses could be attributed to the decomposition of PHB and ESO components, respectively. Therefore, TG analysis allowed for the assessment of the PHB content of the composites from the first weight loss (Table 1). The PHB content of the composites increased as a function of the PHB concentration in DMSO. The first decomposition temperature of the ESO/PHB composites was slightly higher than that of the porous $\mathrm{PHB}$, suggesting that the ESO polymer prevents diffusion of volatile decomposition products. ${ }^{47,48}$

The ESO/PHB composite was soaked in chloroform for $24 \mathrm{~h}$. The PHB component was dissolved in chloroform, and the residue weight was similar to the ESO content obtained by TG analysis. In the SEM image of the residue after the soaking of the composite, pores derived from the depletion of PHB were observed (see the Supplementary Figure S2). These results indicate that the porous structure of PHB is retained without shrinkage during the synthesis of the composite.

DSC measurements of the ESO homopolymer, the porous PHB and the ESO/PHB-100 composite were performed to evaluate the
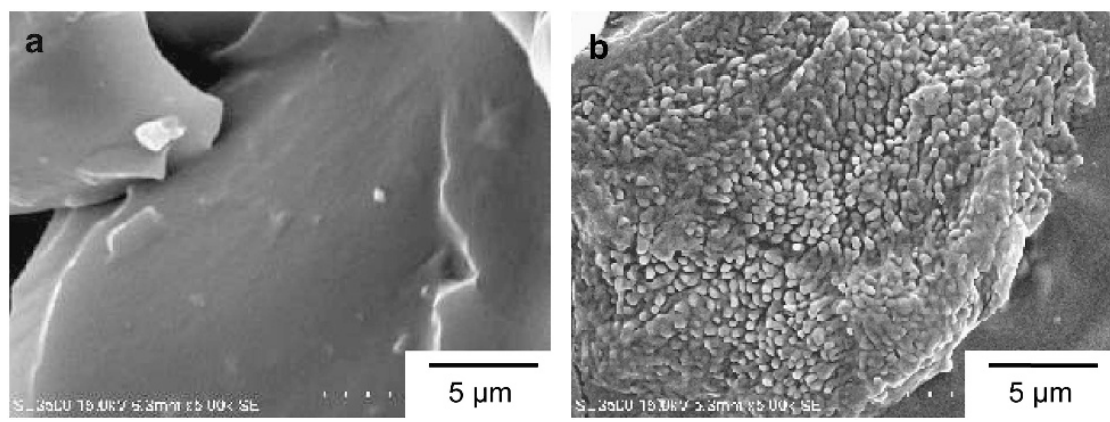

Figure 4 SEM images of the cross-sections of (a) ESO homopolymer and (b) ESO/PHB-100 composite. 


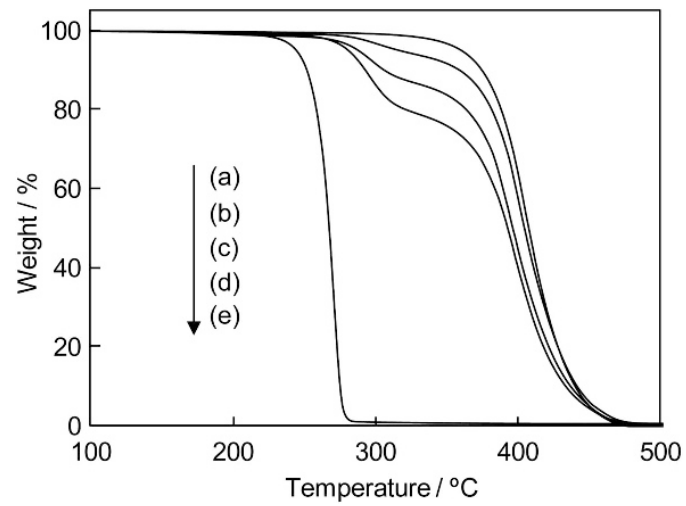

Figure 5 TG traces of (a) ESO homopolymer, (b) ESO/PHB-50, (c) ESO/ PHB-100, (d) ESO/PHB-150 composites and (e) porous PHB.

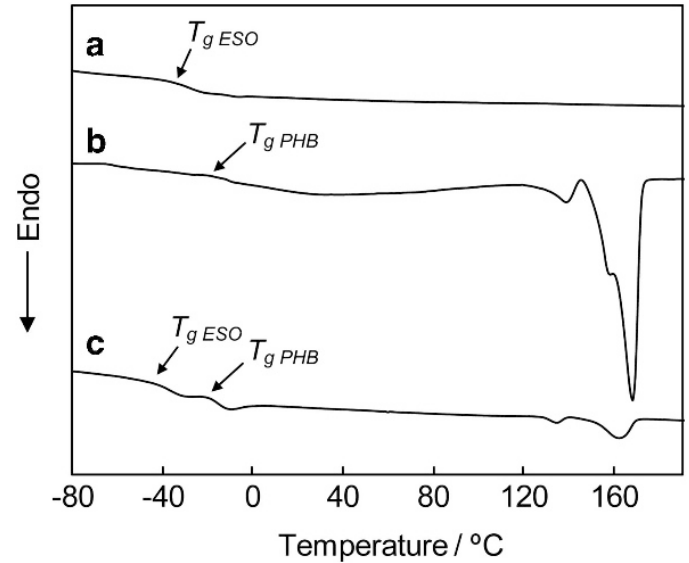

Figure 6 DSC curves of the first heating scan for (a) ESO homopolymer, (b) porous PHB and (c) ESO/PHB-100 composite.

effect of the porous PHB on thermal behaviors (Figure 6). In the first heating curve for the ESO homopolymer, only a glass transition was observed at $-34^{\circ} \mathrm{C}$, whereas the curve for the porous PHB showed a glass transition and melting for $\mathrm{PHB}$ at -16 and $168^{\circ} \mathrm{C}$, respectively. In the curve for the ESO/PHB-100 composite, two glass transitions that are attributed to the ESO polymer and PHB were observed at -45 and $-18^{\circ} \mathrm{C}$, respectively. These data indicate that the majority of the PHB components are immiscible with the ESO polymer. The crystallinity of the PHB component in the ESO/PHB-100 composite was $\sim 60 \%$, and this value barely changed compared with that of the porous PHB (64\%). Furthermore, both curves of the ESO homopolymer and the ESO/PHB composite were almost constant in the higher temperature region, suggesting the quantitative consumption of the oxirane groups of ESO.

Figure 7 shows the dynamic viscoelasticity (storage modulus and loss factor) as a function of temperature for the ESO homopolymer and the ESO/PHB-100 composite. For both samples, the storage moduli remained almost constant at low temperatures between -100 and $-60{ }^{\circ} \mathrm{C}$ and then decreased as the temperature increased. In the rubbery region, the storage modulus of the ESO/PHB composite was higher than that of the ESO homopolymer, suggesting the reinforcement effect of the crystallized PHB. A broad peak of the loss factor of the ESO homopolymer was found near $0^{\circ} \mathrm{C}$, which was regarded as the $\alpha$-transition that corresponds to the glass transition of the ESO

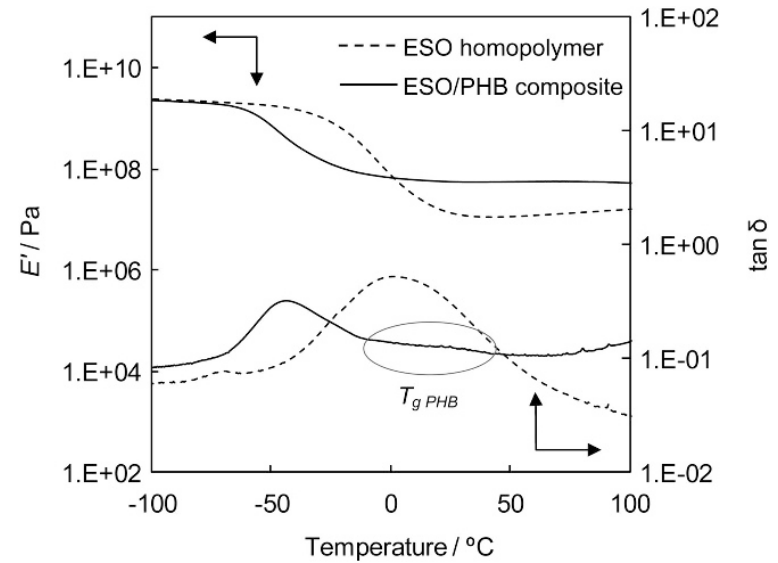

Figure 7 Dynamic viscoelasticity of ESO homopolymer and ESO/PHB-100 composite.

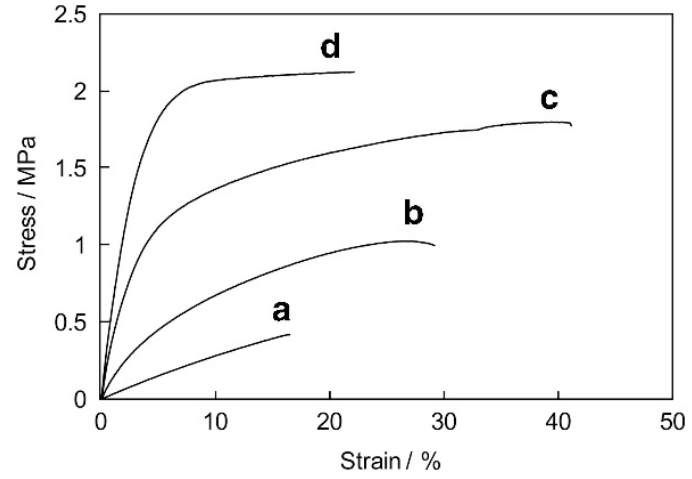

Figure 8 Strain-stress curves of (a) ESO homopolymer, (b) ESO/PHB-50, (c) ESO/PHB-100 and (d) ESO/PHB-150 composites.

polymer. The $\alpha$-transition of the ESO/PHB composite shifted to a lower temperature region. This result could be attributed to the fact that the distance between the crosslinking points becomes longer due to the incorporation of the porous PHB. Moreover, a small peak appeared at $25^{\circ} \mathrm{C}$, which corresponded to the glass transition of PHB. This result is consistent with the DSC analysis.

To evaluate the reinforcement effect of the porous $\mathrm{PHB}$, a tensile test was performed. The strain-stress curves of the ESO homopolymer and the ESO/PHB composites are shown in Figure 8. The porous $\mathrm{PHB}$ was too brittle for the tensile test. The mechanical properties of fiber-reinforced materials are affected by several factors, such as fiber volume, aspect ratio, fiber-matrix adhesion and orientation. Tensile strength and toughness are dependent on the compatibility between the fiber and the matrix, whereas the modulus is influenced by the fiber impregnation or the aspect ratio of the fiber. ${ }^{49}$ The incorporation of the porous PHB increased the Young's modulus and the tensile strength compared with those of the ESO homopolymer. These data indicate the good distribution of the $\mathrm{PHB}$ component in the ESO polymer. Moreover, the strain at break of the ESO/PHB composites was larger than that of the ESO homopolymer. Plant oils are often used as a plasticizer for biopolymers, such as poly(lactic acid) and poly(3-hydroxyalkanoate)s. ${ }^{50-53}$ The three-dimensional fibrous structure of PHB improved the brittleness of the ESO-based network polymer and PHB due to the good interfacial adhesion and 
the formation of the interaction between the ESO chains and the surface of the porous PHB. The improvements in the mechanical properties were dependent on the PHB content of the composites. The Young's modulus and tensile strength of the composites increased as the PHB content increased. However, the largest strain at break was found in the ESO/PHB-100 composite. The decrease in the strain at break in the ESO/PHB-150 composite might be due to the aggregation of $\mathrm{PHB}$ during the phase separation process (see Figure 2c). Moreover, the toughness of the ESO/PHB composites, defined as the area under the strain-stress curve, was much larger than that of the ESO homopolymer. These data imply that the resulting composites possess a great capacity to absorb energy before breaking.

\section{CONCLUSIONS}

In this study, a porous PHB was fabricated via the thermally induced phase separation method using DMSO as a solvent to produce a white material with a three-dimensional interconnected fibrous structure. By changing the concentration of PHB in DMSO, the formation and structure of the porous PHB could be easily controlled. The porous PHB was immersed in ESO with a thermally latent catalyst, and the subsequent curing of ESO afforded the ESO/PHB composite. The resulting composites were relatively transparent due to the nanoscale fibrous structure of PHB. The DSC and DMA results of the composite showed two glass transitions, as well as the melting of $\mathrm{PHB}$. The Young's modulus and the tensile strength of the ESO/PHB composites were larger than those of the ESO homopolymer. The incorporation of the porous $\mathrm{PHB}$ also increased the strain at break, indicating that the resulting composites are effectively reinforced without sacrificing toughness.

Because the present composite consists of plant oil and bacterial polyester, the biomass content of the composite was $100 \%$. Therefore, this study provides a novel method for designing and synthesizing full bio-based composite materials.

\section{ACKNOWLEDGEMENTS}

This study was supported by the New Energy and Industrial Technology Development Organization (NEDO) of Japan.

1 Biermann, U., Friedt, W., Lang, S., Lühs, W., Machmüller, G., Metzger, J. O., Klaas, M. R., Schäfer, H. J. \& Schneider, M. P. New Syntheses with Oils and Fats as Renewable Raw Materials for the Chemical Industry. Angew. Chem. Int. Ed. 39, 2206-2224 (2000).

2 Ragauskas, A. J., Williams, C. K., Davison, B. H., Britovsek, G., Cairney, J., Eckert, C. A., Frederick, W. J. Jr., Hallett, J. P., Leak, D. J., Liotta, C. L., Mielenz, J. R., Murphy, R., Templer, R. \& Tschaplinski, T. The Path Forward for Biofuels and Biomaterials. Science 311, 484-489 (2006).

3 Nagarajan, V., Mohanty, A. K. \& Misra, M. Sustainable Green Composites: Value Addition to Agricultural Residues and Perennial Grasses. ACS Sustainable Chem. Eng. 1, 325-333 (2013).

4 Mecking, S. Nature or Petrochemistry? Biologically Degradable Materials. Angew. Chem. Int. Ed. 43, 1078-1085 (2004).

5 Khot, S. N., Lascala, J. J., Can, E., Morye, S. S., Williams, G. I., Palmese, G. R., Kusefoglu, S. H. \& Wool, R. P. Development and Application of Triglyceride-based Polymers and Composites. J. Appl. Polym. Sci. 82, 703-723 (2001).

6 Metzger, J. O. \& Bronscheuer, U. Lipids as Renewable Resources: Current State of Chemical and Biotechnological Conversion and Diversification. Appl. Microbiol. Biotechnol. 71, 13-22 (2006).

7 Kumar, A., Vemula, P. K., Ajayan, P. M. \& John, G. Silver-nanoparticle-embedded Antimicrobial Paints Based on Vegetable Oil. Nat. Mater. 7, 236-241 (2008).

8 Petrović, Z. S. Polyurethanes from Vegetable Oils. Polym. Rev. 48, 109-155 (2008).

9 Swern, D., Billen, G. N., Findley, T. W. \& Scanlan, J. T. Hydroxylation of Monounsaturated Fatty Materials with Hydrogen Peroxide. J. Am. Chem. Soc. 67, 1786-1789 (1945).
10 Biresaw, G., Liu, Z. S. \& Erhan, S. Z. Investigation of the Surface Properties of Polymeric Soaps Obtained by Ring-opening Polymerization of Epoxidized Soybean Oil. J. Appl. Polym. Sci. 108, 1976-1985 (2008).

11 Chakrapani, S. \& Crivello, J. V. Synthesis and Photoinitiated Cationic Polymerization of Epoxidized Castor Oil and Its Derivatives. J. Macromol. Sci. Pure Appl. Chem. A35, 1-20 (1998).

12 Wool, R. P. Development of Affordable Soy-based Plastics, Resins, and Adhesives. CHEMTECH 29, 44-48 (1999).

13 Tran, P., Graiver, D. \& Narayan, R. Biocomposites Synthesized from Chemically Modified Soy Oil and Biofibers. J. Appl. Polym. Sci. 102, 69-75 (2006).

14 Tsujimoto, T., Imai, N., Kageyama, H., Uyama, H. \& Funaoka, M. Network Polymers from Epoxidized Soybean Oil and Bio-based Phenolic Polymers. J. Network Polym. Jpn 29, 192-197 (2008).

15 Campanella, A., La Scala, J. J. \& Wool, R. P. The Use of Acrylated Fatty Acid Methyl Esters as Styrene Replacements in Triglyceride-based Thermosetting Polymers. Polym. Eng. Sci. 49, 2384-2392 (2009).

16 Nelson, T. J., Galhenage, T. P. \& Webster, D. C. Catalyzed Crosslinking of Highly Functional Biobased Epoxy Resins. J. Coat. Technol. Res. 10, 589-600 (2013).

17 Tsujimoto, T., Uyama, H. \& Kobayashi, S. Green Nanocomposites from Renewable Resources: Biodegradable Plant Oil-silica Hybrid Coatings. Macromol. Rapid Commun. 24, 711-714 (2003).

18 Uyama, H., Kuwabara, M., Tsujimoto, T., Nakano, M., Usuki, A. \& Kobayashi, S. Green Nanocomposites from Renewable Resources: Plant Oil-clay Hybrid Materials. Chem. Mater. 15, 2492-2494 (2003).

19 Miyagawa, H., Misra, M., Drazal, L. T. \& Mohanty, A. K. Novel Biobased Nanocomposites from Functionalized Vegetable Oil and Organically-modified Layered Silicate Clay. Polymer. (Guildf). 46, 445-453 (2005).

20 Lligadas, G., Randa, J. C., Galia, M. \& Cádiz, V. Bionanocomposites from Renewable Resources: Epoxidized Linseed Oil-polyhedral Oligomeric Silsesquioxanes Hybrid Materials. Biomacromolecules 7, 3521-3526 (2006).

21 Tsujimoto, T., Uyama, H. \& Kobayashi, S. Synthesis of High-performance Green Nanocomposites from Renewable Natural Oils. Polym. Degrad. Stab. 95, 1399-1405 (2010).

22 Williams, G. I. \& Wool, R. P. Composites from Natural Fibers and Soy Oil Resins. Appl. Composite Mater. 7, 421-432 (2000).

23 Rakotonirainy, A. M. \& Padua, G. W. Effects of Lamination and Coating with Drying Oils on Tensile and Barrier Properties of Zein Films. J. Agric. Food Chem. 49, 2860-2863 (2001).

24 Shibata, M., Teramoto, N., Someya, Y. \& Suzuki, S. Bio-based Nanocomposites Composed of Photo-cured Epoxidized Soybean Oil and Supramolecular Hydroxystearic Acid Nanofibers. J. Polym. Sci. B. Polym. Phys. 47, 669-673 (2009).

25 Tsujimoto, T., Ohta, E. \& Uyama, H. Bio-based Composites from Epoxidized Plant Oil and Cellulose Gel. J. Network Polym. Jpn 34, 85-89 (2013).

26 Imai, N., Kageyama, H. \& Uyama, H. High-performance Nanofiber-reinforeced Composite from All Bio-based Materials. Chem. Lett. 36, 698-699 (2007).

27 Holland, S. J., Jolly, A. M., Yasin, M. \& Tighe, B. J. Polymers for Biodegradable Medical Devices, II. Hydoroxybutyrate-hydroxyvalerate Copolymers: Hydrolytic Studies. Biomater. 8, 289-295 (1987).

28 Doi, Y. Microbial Polyesters 1-166 (VCH Publishers, New York, 1990).

29 Barham, P. J., Keller, A., Otun, E. L. \& Holmes, P. A. Crystallization and Morphology of a Bacterial Thermoplastic: Poly-3-hydroxybutyrate Single-cell Protein and Related Technology. J. Matter. Sci. 19, 2781-2794 (1984).

30 Inoue, Y. \& Yoshie, N. Structure and Physical Properties of Bacterially Synthesized Polyesters. Prog. Polym. Sci. 17, 571-610 (1992).

31 Homes, P. A. Application of PHB: A Microbially Produced Biodegradable Thermoplastic. Phys. Technol. 16, 32-36 (1985).

32 Doi, Y., Tamaki, A., Kunioka, M. \& Soga, K. Production of Copolyesters of 3-Hydroxybutyrate and 3-Hydroxyvalerate by A/caligenes eutrophus from Butyric and Pentanoic Acids. Appl. Microbiol. Biotechnol. 28, 330-334 (1988).

33 Verhoogt, H., Ramsay, B. A. \& Favis, B. D. Polymer Blends Containing Poly (3-hydroxyalkanoate)s. Polymer. (Guildf). 35, 5155-5169 (1994).

34 Doi, Y., Kitamura, S. \& Abe, H. Microbial Synthesis and Characterization of Poly(3-hydroxybutyrate-co-3-hydroxyhexanoate). Macromolecules 28, 4822-4828 (1995).

35 Xie, Y., Kohls, D., Noda, I., Schaefer, D. W. \& Akpalu, Y. A. Poly(3-hydroxybutyrate-co3-hydroxyhexanoate) Nanocomposites with Optimal Mechanical Properties. Polymer. (Guildf). 50, 4656-4670 (2009).

36 Xin, Y. \& Uyama, H. Fabrication of Polycarbonate and Poly(3-hydroxybutyrate-co-3hydroxyhexanoate) Blend Monolith via Non-solvent-induced Phase Separation Method. Chem. Lett. 41, 1509-1511 (2012).

37 Kistler, S. S. Coherent Expanded Aerogels and Jellies. Nature 127, 741 (1931).

38 Hüsing, N. \& Schubert, U. Aerogels-airy Materials: Chemistry, Structure and Properties. Angew. Chem. Int. Ed. 37, 22-45 (1998).

39 Mayr, M., Mayr, B. \& Buchmeiser, M. R. Monolithic Materials: New High-performance Supports for Permanently Immobilized Metathesis Catalysts. Angew. Chem. Int. Ed. 40, 3839-3842 (2001).

40 Shih, Y. H., Singco, B., Liu, W. L., Hsu, C. H. \& Huang, H. Y. A Rapid Synthetic Method for Organic Polymer-based Monoliths in a Room Temperature Ionic Liquid Medium via Microwave-assisted Vinylization and Polymerization. Green. Chem. 13, 296-299 (2011).

41 Isobe, N., Sekine, M., Kimura, S., Wada, M. \& Kuga, S. Anomalous Reinforcing Effects in Cellulose Gel-based Polymeric Nanocomposites. Cellulose 18, 327-333 (2011). 
42 Kadokawa, J., Takegawa, A., Mine, S. \& Prasad, K. Preparation of Chitin Nanowhiskers Using an Ionic Liquid and Their Composite Materials with Poly(vinyl alcohol). Carbohydr. Polym. 84, 1408-1412 (2011).

43 Okada, K., Nandi, M., Maruyama, J., Oka, T., Tsujimoto, T., Kondoh, K. \& Uyama, H. Fabrication of Mesoporous Polymer Monolith: a Template-free Approach. Chem. Commun. 47, 7422-7424 (2011).

44 Liu, S., Yan, Q., Tao, D., Yu, T. \& Liu, X. Highly Flexible Magnetic Composite Aerogels Prepared by Using Cellulose Nanofibril Networks as Templates. Carbohydr. Polym. 89, 551-557 (2012).

45 Hayase, G., Kanamori, K., Hasegawa, G., Maeno, A., Kaji, H. \& Nakanishi, K. A Superamphiphobic Macroporous Silicone Monolith with Marshmallow-like Flexibility. Angew. Chem. Int. Ed. 52, 10788-10791 (2013).

46 Hosoda, N., Tsujimoto, T. \& Uyama, H. Green Composite of Poly(3-hydroxybutyrate-co3-hydroxyhexanoate) Reinforced with Porous Cellulose. ACS Sustainable Chem. Eng. doi:10.1021/sc400290y in press.

47 Agrawal, M., Gupta, S., Zafeiropoulos, N. E., Oertel, U., Häßler, R. \& Stamm, M. Nanolevel Mixing of ZnO into Poly(methyl methacrylate). Macromol. Chem. Phys. 211, 1925-1932 (2010).
48 Fahma, F., Hori, N., Iwata, T. \& Takemura, A. The Morphology and Properties of Poly(methyl methacrylate)-Cellulose Nanocomposites Prepared by Immersion Precipitation Method. J. Appl. Polym. Sci. 130, 1563-1568.

49 Eichhorn, S. J., Baillie, C. A., Zafeiropoulos, N., Mwaikambo, L. Y., Ansell, M. P. Dufrense, A., Entwistle, K. M., Herrera-Franco, P. J., Escamilla, G. C., Groom, L., Hughes, M., Hill, S. C., Rials, T. G. \& Wild, P. M. Review: Current International Research into Cellulosic Fibres and Composites. J. Mater. Sci. 31, 2107-2131 (2001).

50 Cecorulli, G., Pizzoli, M. \& Scandola, M. Plasticization of Bacterial Poly(3-hydroxybutyrate). Macromolecules 25, 3304-3306 (1992).

51 Ishiaku, U. S., Shaharum, A., Ismail, H. \& Mohd Ishak, Z. A. The Effect of an Epoxidized Plasticizer on the Thermo-oxidative Ageing of Poly(vinyl chloride)/epoxidized Natural Rubber Thermoplastic Elastomers. Polym. Int. 45, 83-91 (1997).

52 Choi, J. S. \& Park, W. O. Effect of Biodegradable Plasticizers on Thermal and Mechanical Properties of Poly(3-hydroxybutyrate). Polym. Test. 23, 455-460 (2004).

53 Robertson, M. L. Chang, K., Gramlich, W. M. \& Hillmyer, M. A. Toughening of Polylactide with Polymerized Soybean Oil. Macromolecules 43, 1807-1814 (2010).

Supplementary Information accompanies the paper on Polymer Journal website (http://www.nature.com/pj) 